\title{
DINÂMICA DE USO DA TERRA EM SENADOR JOSÉ PORFÍRIO-PA, AMAZÔNIA ORIENTAL
}

\section{DYNAMICS OF LAND USE IN SENADOR JOSÉ PORFÍRIO-PA, EASTERN AMAZON}

\section{DINÁMICA DEL USO DE LA TIERRA EN SENADOR JOSÉ PORFÍRIO-PA, AMAZONIA ORIENTAL}

\author{
Valdinei Mendes Moura ${ }^{1}$ https://orcid.org/0000-0002-6926-5694 \\ José Antônio Magalhâes Marinho² https://orcid.org/0000-0001-9870-6930 \\ Gabriel Alves Veloso ${ }^{3}$ https://orcid.org/0000-0002-3655-4166
}

\footnotetext{
${ }^{1}$ Mestrando em Geografia - Universidade Federal do Pará. E-mail: valdinei.pafor.2011@ @otmail.com

2 Doutor em Geografia - USP. Professor Adjunto da Universidade Federal do Pará, campus Altamira. E-mail: josemarinho@ ufpa.br

${ }^{3}$ Doutor em Geografia - UFG. Professor Adjunto da Universidade Federal do Pará, campus Altamira. E-mail: gveloso@ufpa.br
}

\section{RESUMO}

Na região de Integração do Xingu a dinâmica do uso e cobertura da terra perpassa por transformações aceleradas, consolidadas principalmente por redes de transportes rodoviárias, sobretudo a partir da década de 70, com a abertura da rodovia Transamazônica. Dessa forma, nesse artigo se priorizou analisar a dinâmica de uso e cobertura da terra no município de Senador José Porfírio, inserido em uma área de intensa mudança, principalmente após a instalação da Usina Hidroelétrica de Belo Monte. Nesse sentido, os procedimentos metodológicos utilizados centraram-se no levantamento de informações e dados em bases digitais, e na subsequente análise e interpretação do material obtido e pesquisa bibliográfica sobre a dinâmica dos usos da terra na região amazônica. O objetivo da pesquisa foi analisar a dinâmica de uso da terra no município de Senador José Porfírio, no período de 2010 a 2019, considerando os aspectos históricos e econômicos, assim como suas expressões socioambientais, paisagísticas e territoriais. Nos resultados e discussões constatou-se que as áreas de agricultura sofreram variações, com expansão do cultivo do cacao, além disso, contatou-se que a extração ilegal de madeira, e consequentemente o desmatamento para produção agropecuária vem avançando principalmente sobre as áreas de assentamentos e terras indígenas.

Palavras-chave: Região do Xingu. Dinâmicas territoriais. Impactos Ambientais.

\begin{abstract}
In the Xingu Integration region, the dynamics of land use and coverage go through accelerated transformations, consolidated mainly by road transport networks, especially from the 1970s onwards, with the opening of the Transamazônica highway. Thus, in this article, it was prioritized to analyze the
\end{abstract}


Dinâmica de Uso da Terra em Senador José Porfírio - PA, Amazônia Oriental Valdinei Mendes Moura; José Antônio Magalhâes Marinho; Gabriel Alves Veloso

dynamics of land use and coverage in the municipality of Senador José Porfírio, inserted in an area of intense change, mainly after the installation of the Belo Monte Hydroelectric Plant. In this sense, the methodological procedures used were centered on gathering information and data on digital bases, and on the subsequent analysis and interpretation of the material obtained and bibliographical research on the dynamics of land uses in the Amazon region. The objective of the research was to analyze the dynamics of land use in the municipality of Senador José Porfírio, from 2010 to 2019, considering the historical and economic aspects, as well as their socio-environmental, landscape, and territorial expressions. In the results and discussions, it was found that the agricultural areas suffered variations, with the expansion of the cultivation of cacao, in addition, it was found that the illegal extraction of wood, and consequently the deforestation for agricultural production has been advancing mainly on the settlement areas and indigenous lands.

Keywords: Xingu Region. Territorial dynamics. Environmental impacts.

\section{RESUMEN}

En la región de Integración Xingu, la dinámica de uso y cobertura del suelo pasa por transformaciones aceleradas, consolidadas principalmente por las redes de transporte por carretera, especialmente a partir de la década de 1970, con la apertura de la carretera Transamazônica. Así, en este artículo se priorizó analizar la dinámica de uso y cobertura del suelo en el municipio Senador José Porfírio, insertado en una zona de intenso cambio, principalmente tras la instalación de la Central Hidroeléctrica Belo Monte. En este sentido, los procedimientos metodológicos utilizados se centraron en la recopilación de información y datos en bases digitales, y en el posterior análisis e interpretación del material obtenido y la investigación bibliográfica sobre la dinámica de los usos del suelo en la región amazónica. El objetivo de la investigación fue analizar la dinámica del uso del suelo en el municipio Senador José Porfírio, de 2010 a 2019, considerando los aspectos históricos y económicos, así como sus expresiones socioambientales, paisajísticas y territoriales. En los resultados y discusiones se encontró que las áreas de agricultura sufrieron variaciones, con expansión del cultivo de cacao, además, se encontró que la extracción ilegal de madera, y consecuentemente la deforestación para la producción agrícola ha ido avanzando principalmente en la áreas de asentamientos y tierras indígenas.

Palabras clave: Región de Xingu. Dinámica territorial. Impactos ambientales.

\section{INTRODUÇÃO}

O processo de degradação ambiental na Amazônia encontra-se intimamente ligado forma de ocupação econômica da região implementada a partir da segunda metade do século XX. Tal processo, marcado pela ampliação da propriedade privada da terra e pela mercantilização dos recursos naturais, ensejou o avanço da concentração e grilagem de terras públicas (OLIVEIRA; FARIA; HOLLANDA, 2017), bem como a constante violência contra povos e grupos sociais do campo (MARTINS, 1984; BARATA, 1995).

No começo do século XXI, o processo de ocupação econômica na Amazônia passou a envolver mais fortemente, além da luta pela terra e pelos recursos florestais e minerais, a disputa pelo controle de grandes rios na região para geração de energia elétrica. Nesse quadro, ocorre o barramento do rio Madeira em Rondônia, para a construção das hidrelétricas de Jirau e Santo 
Antônio, e no rio Xingu no Pará, instala-se a maior hidrelétrica eminentemente brasileira, a UHE Belo Monte (MARINHO, 2019; BORGES, 2018).

$\mathrm{Na}$ Amazônia oriental, em particular, uma área que vem chamando a atenção pela convergência dessas diferentes formas de uso da terra (e das águas evidentemente) e suas consequências socioambientais é a Região de Integração (RI) do Xingu ${ }^{1}$, no oeste do Estado do Pará. Esta região é composta por nove municípios (Altamira, Anapu, Brasil Novo, Medicilândia, Pacajá, Placas, Porto do Moz, Senador José Porfírio, Uruará e Vitória do Xingu) e vem apresentando um dinâmico processo de mudança no padrão de uso da terra, desde a construção da BR 230, iniciada na década de 1970 (CANTO et. al., 2015).

Tais mudanças vinculam-se fortemente ao avanço da exploração madeireira e, sobretudo, da pecuária extensiva. A expansão dessas atividades econômicas, historicamente praticadas Amazônia, encontra-se diretamente atrelada à exploração indiscriminada da floresta, ao desmatamento e à apropriação ilegal de terras públicas, através da grilagem (TORRES, 2012; BARRETO, 2007).

A implantação da usina hidroelétrica Belo Monte no médio rio Xingu, também desencadeou profundas mudanças sociais e ambientais nessa região do Pará. Geograficamente, essas mudanças materializaram-se através do barramento do rio Xingu, com a criação de canais e lagos artificiais, que redirecionaram o fluxo da água do rio e provocaram redução significativa da vazão em extenso trecho da área conhecida como volta grande do Xingu, atingindo diferentes grupos sociais que se reproduziam nesse trecho do rio, sobretudo pelos impactos negativos na atividade da pesca (CORREA, 2019).

Um dos municípios em que esses processos de uso da terra vêm avançando intensamente é Senador José Porfírio. Não obstante a implementação de um ordenamento territorial pautado no discurso da preservação ambiental (MOURA, 2015), no território desse município vem ocorrendo mudanças impulsionadas pelo avanço das atividades agropecuárias e pela ação de agentes interessados em explorar e/ou apropriar-se de áreas ainda florestadas, inclusive no interior de Terra Indígena em fase de estudo (Ituna/Itatá). Assim, o desmatamento avança, ameaçando não apenas a biodiversidade, mas os modos de vida de comunidades ribeirinhas e povos originários (GREENPEACE, 2021; SILVA, 2019).

\footnotetext{
${ }^{1}$ Essa região surgiu na nova proposta de regionalização para o estado do Pará, em que se verificou que as regionalizações estabelecidas pelo Instituto Brasileiro de Geografia e Estatística (IBGE) - Mesorregião e Microrregião - não mais correspondiam à realidade estadual. Nessa nova regionalização do estado, a partir de critérios características como concentração populacional, acessibilidade, complementaridade e interdependência econômica, foram reconhecidas 12 Regiões de Integração, dentre as quais a Região de Integração do Xingu (CANTO et al., 2015).
} 
Dessa forma, importa discutir esse intenso processo de antropização em Senador José Porfírio, de modo a evidenciar sua dinâmica de uso da terra e suas consequências socioambientais. Sem perder de vista que essa dinâmica não apenas desorganiza os circuitos geobiofísicos, como gera conflitos sociais e ameaça povos originários e suas culturas.

Assim, objetivou-se analisar a dinâmica de uso da terra no município de Senador José Porfírio, no período de 2010 a 2019, considerando os aspectos históricos e econômicos, assim como suas expressões socioambientais, paisagísticas e territoriais.

\section{ÁREA DE ESTUDO}

O município de Senador José Porfírio ocupa uma área de aproximadamente 14.419,92 $\mathrm{Km}^{2}$, correspondendo a 5,75\% da Região de Integração Xingu e 1,16\% do Estado do Pará (IDESP, 2011). O mesmo encontra-se a 403,34 km da capital do Estado e limita-se ao norte com o município de Porto de Moz, a Leste com os municípios de Portel e Anapu, ao sul com o município de São Felix do Xingu e a oeste com os municípios de Altamira, Porto de Moz e Vitória do Xingu (IDESP, 2011).

A sede municipal está localizada à margem direita do Rio Xingu (Figura 01), a jusante do perímetro conhecido como Volta Grande, entre os igarapés Croatá e Maxiacá, com as seguintes coordenadas geográficas: $02^{\circ} 34^{\prime} 45^{\prime}$ 'S e $51^{\circ} 57^{\prime} 15^{\prime}$ W. Também, é um dos dois únicos municípios brasileiros que apresenta enclaves, isto é, dois territórios totalmente separados (IDESP, 2011), ou seja, trata-se de um município que apresenta em seu conjunto territorial, características peculiares, chamando a atenção sua descontinuidade territorial (MOURA, 2015).

As duas porções territoriais que formam o município de Senador José Porfírio estão separadas entre si pelos municípios de Anapu e Vitória do Xingu (Figura 1). Na porção territorial mais ao norte, de menor extensão geográfica, é onde situa-se a sede municipal de Senador, e na porção territorial ao sul, que é bem mais extensa, encontram-se terras indígenas, unidades de conservação e localidades como Ilha da Fazenda e Ressaca, situadas às margens do rio Xingu, no trecho de vazão reduzida da UHE Belo Monte.

Há dificuldades de conexão entre essas duas porções territoriais, devido à insuficiência logística e à necessidade de atravessar municípios vizinhos como Anapu, Vitória do Xingu e Altamira, para deslocar-se de uma porção à outra do município (MOURA, 2015). 
Dinâmica de Uso da Terra em Senador José Porfírio - PA, Amazônia Oriental

Valdinei Mendes Moura; José Antônio Magalhâes Marinho; Gabriel Alves Veloso

Figura 01 - Mapa de Localização do município estudado.

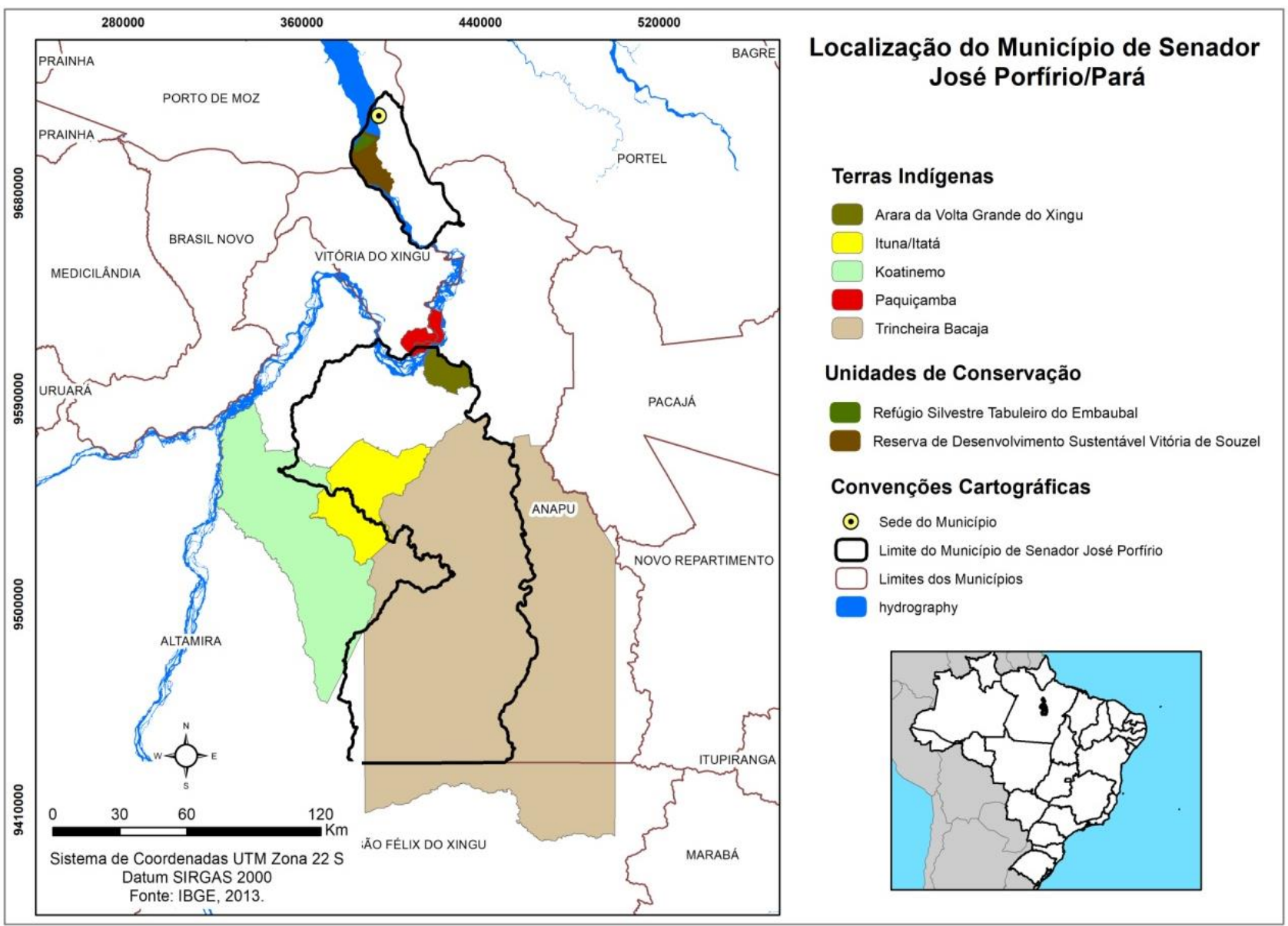

Fonte: MAPBIOMAS (2020)

\section{MATERIAL E MÉTODOS}

Os procedimentos metodológicos utilizados nessa pesquisa centraram-se no levantamento de informações e dados em bases digitais, e na subsequente análise e interpretação do material obtido. Dessa maneira, na primeira etapa do trabalho, foi realizada pesquisa bibliográfica em bases digitais, buscando estudos sobre a dinâmica dos usos da terra na região amazônica e sobre a utilização das geotecnologias como ferramentas para monitorar a dinâmica territorial desses usos, particularmente em relação ao processo de desmatamento, um dos temas mais sensíveis na questão ambiental atualmente.

Na segunda etapa do trabalho, buscaram-se no site do Projeto de Mapeamento Anual da Cobertura e Uso da terra do Brasil - Mapbiomas, Instituto Brasileiro de Geografia e Estatístico (IBGE) e Instituto Socioambiental (ISA), os dados de uso do solo e ocupação do município de Senador José Porfírio relativos ao período de 2010 a 2018. O mesmo sendo feito no PRODES 2019 (Coordenação-Geral de Observação da Terra-OBT/INPE). 
Com esses dados foram elaborados os gráficos e tabelas, além de cálculos de área obtidos no site PRODES, para possibilitar uma análise do uso e cobertura da terra no município de Senador José Porfírio. Adicionalmente, também foram elaborados mapas com o intuito de auxiliar visualmente os processos estudados.

\section{RESULTADOS E DISCUSSÃO}

Nas séries históricas de 2010 a 2019, analisadas através do Sistema de Informações Geográfica - SIG's, bem como na pesquisa bibliográfica acerca das dinâmicas de uso da terra em Senador José Porfírio, observa-se que nesse município existe um cenário de pressão sobre os recursos naturais (terra, água, florestas), com permanente elevação das taxas de desmatamento, levando o município, na década passada, a fazer parte da lista dos municípios que mais se desmatam no Brasil. A seguir, examinam-se alguns processos de uso da terra que apresentam maior expressividade em Senador José Porfírio, com o intuito de avaliar mais detidamente seus efeitos socioambientais, particularmente no que diz respeito à cobertura vegetal.

\section{A DINÂMICA DA AGRICULTURA}

A atividade agrícola em Senador José Porfírio é marcada por um leque diversificado de cultivos perenes e temporários comum à agricultura camponesa na Amazônia. Nesse leque destacam-se o cultivo de milho, mandioca, macaxeira, arroz, feijão, abacaxi, limão e cacau, sendo a maior parte dessa produção oriunda dos assentamentos rurais (FILHO; NERES, 2016).

O cultivo desses produtos agrícolas, como em outras áreas da Amazônia (SERRÃO; CRUZ, 2019), também é praticado pelos camponeses ribeirinhos de maneira combinada com a pesca artesanal e com diversos tipos de extrativismos. Na comunidade da Ressaca, por exemplo, situada na Volta Grande do Xingu, os camponeses, além do trabalho na roça, ocupam-se também com a pesca e o garimpo, sendo a partir desse leque de atividades que conseguem manter o processo de reprodução social às margens do Xingu (MAIA; GUERRA, 2015).

Com isso, as áreas destinadas aos cultivos anuais e perenes em Senador José Porfírio, são consideradas modestas até para os padrões de produção familiar camponesa (FILHO; NERES, 2016). E contribui para isso, a escassez de financiamento para fomento da produção agrícola. Em certos casos, somente depois de mais de uma década que famílias assentadas da reforma agrária em Senador José Porfírio, voltarão a receber crédito rural, por meio de uma parceria entre o escritório local da Empresa de Assistência Técnica e Extensão Rural do Estado 
do Pará (Emater), Instituto Nacional de Colonização e Reforma Agrária (Incra) e organizações sociais de agricultores (EMATER, 2020).

Importa mencionar uma parceria entre a Superintendência Regional do INCRA no Oeste do Pará, por meio da Unidade Avançada de Altamira, e a Prefeitura Municipal de Senador José Porfírio que viabilizou a construção de 16 pontes em estradas vicinais que dão acesso ao Projeto de Assentamento no município (INCRA, 2020). Tais iniciativas contribuem para melhorar o escoamento da produção agrícola. Com isso, verifica-se que a produção de cacau vem se elevando nos últimos anos, como se observa no quadro a seguir (Quadro 01). Em relação à área destinada à colheita, constata-se uma elevação de uso e ocupação da terra entre os anos de 2010 a 2019 da ordem de 3.074\%, segundo dados levantados pelo IBGE (IBGE, 2020).

Quadro (01) de produção agrícola: lavoura permanente de cacau.

\begin{tabular}{|c|c|c|c|}
\hline Ano & $\begin{array}{c}\text { Área Destinada a } \\
\text { Colheita } \\
\text { (ha) }\end{array}$ & $\begin{array}{c}\text { Quantidade de } \\
\text { Amêndoas } \\
\text { (Toneladas) }\end{array}$ & $\begin{array}{c}\text { Valor da } \\
\text { Produção } \\
\text { (x 1000) R\$ }\end{array}$ \\
\hline 2010 & 135 & 81 & 405,00 \\
\hline 2011 & 235 & 141 & 705,00 \\
\hline 2012 & 730 & 438 & $2.008,00$ \\
\hline 2013 & 944 & 1.210 & $3.954,00$ \\
\hline 2014 & 1.060 & 814 & $5.511,00$ \\
\hline 2015 & 1.060 & 827 & $5.789,00$ \\
\hline 2016 & 1.800 & 782 & $7.820,00$ \\
\hline 2017 & 1.800 & 1.381 & $9.943,00$ \\
\hline 2018 & 1.800 & 1.381 & $13.810,00$ \\
\hline 2019 & 4.151 & 4.658 & $45.658,00$ \\
\hline & Elaboração: MOURA, V. M $(2020)$ \\
\hline
\end{tabular}

Além disso, o IBGE (2020) constatou um aumento considerável na quantidade de amêndoas em toneladas, sendo que esse percentual aumentou entre os anos de 2010 a 2013 em 1.493\%. Em relação aos anos de 2013 a 2019 a quantidade de amêndoas em toneladas atingiu o percentual de $385 \%$, predominantemente na porção sul do município.

Em síntese, a comercialização da produção agrícola da porção norte do município é pequena. Isso é perceptível pela baixa oferta de produtos no mercado municipal, resumindo-se à comercialização de macaxeira, folhas, melancia e abacaxi, entre outros produtos em pequena escala.

\section{A DINÂMICA DA PECUÁRIA}


A pecuária é uma das formas de uso da terra mais dinâmicas em Senador José Porfírio, entretanto, é necessário combater a ocupação ilegal e o desmatamento de terras públicas florestadas, sendo na maioria dos casos relacionados com essa atividade (IMAZON, 2015). Isso ocorre devido à escassez de terras baratas para expandir a pecuária extensiva, estimulando os produtores a aumentarem a produtividade em áreas já desmatadas. Todavia, as florestas públicas deveriam ser destinadas para produção (madeira e outros produtos) por meio de manejo florestal, o que permitiria conciliar crescimento econômico e conservação.

Na figura 02, observa-se a elevação do efetivo bovino no município, no período de 2010 a 2018, sendo possível observar que o rebanho apresentou um crescimento de 44.467 cabeças em 2010, para 79.920 animais em 2018, um aumento da ordem de 56\% em oito anos (IBGE, 2019).

Figura 02 - Efetivo Bovino no Município de Senador José Porfírio

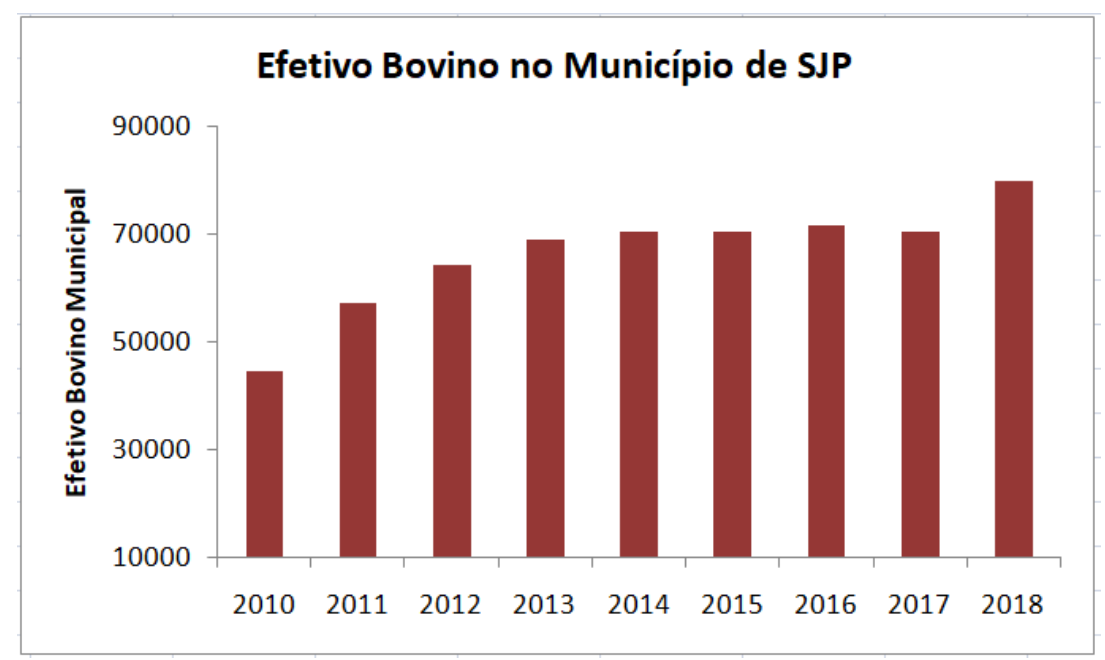

Fonte: IBGE (2019)

Nesse sentido, o avanço das áreas de pastagens para prática da pecuária extensiva, particularmente na porção sul do município constitui um vetor de uso e ocupação da terra que está relacionado às tensões e conflitos fundiários e, sobretudo, à dinâmica de desmatamento, inclusive no interior dessas terras indígenas.

Como se trata de uma pecuária eminentemente extensiva, as áreas de pastagens avançaram no município, como pode ser observado no gráfico 3 (Figura 03). Observa-se que em Senador José Porfírio, no período de 2010 a 2018, ocorreu crescente expansão das áreas de pastagens, atingindo no último ano do período analisado de 94.757,20 ha, o que é equivalente a 6,5\% da área do município, com um crescimento da ordem de $27 \%$ entre 2010 e 2018. 
Figura 03 - Crescimento das Áreas de Pastagem no Município Estudado

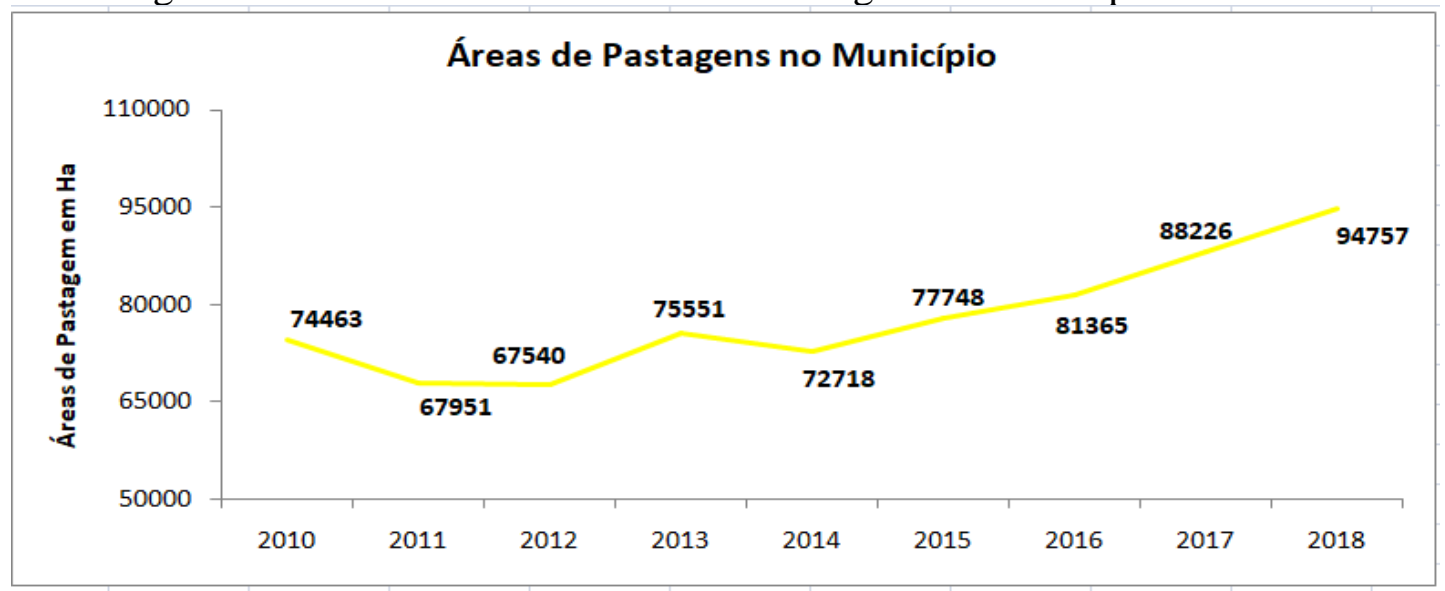

Fonte: MAPBIOMAS (2020).

No período 2010 a 2018, o avanço das pastagens em Senador José Porfírio, materializa-se tanto na porção territorial norte, quanto na porção sul do município que, em sua grande parte, é ocupada por assentamentos rurais e terras indígenas, como se observa no mapa da figura 04. Essa expansão da pecuária no município pode ser explicada pelos baixos preços das terras praticados no bioma Amazônico, que permite o aumento da produção com um investimento relativamente pequeno, sendo que os preços das terras em pastagem na região entre os anos de 1970 e 2000, foi de cerca de cinco a dez vezes mais baixos que os preços praticados em São Paulo. E, em 2002, equivalia de 35\% a 65\% dos preços praticados na região Centro-Sul (IMAZON, 2015). Portanto, na Amazônia e no Pará, em particular, o baixo preço das terras, muitas vezes griladas (TORRES, 2017), é um dos principais fatores para a expansão da pecuária extensiva.

Como se pode observar na figura 04, na porção sul do município, predominantemente nas áreas mais próximas ao rio Xingu (PA Ressaca; PDS Ituna, Gleba Bacajaí), que a expansão das áreas de pastagem está indo na direção mais ao sul de Senador José Porfírio, onde se localizam as seguintes Terras Indígenas: Arara da Volta Grande do Xingu, Trincheira Bacajá, Ituna/Itatá e Koatinemo. Essas áreas vêm ganhando destaque pela intensa mudança de uso da terra, com a supressão das áreas de floresta, o que pode indicar extração ilegal de madeira (atividade comum na região), bem como pela expansão da pecuária extensiva. 
Dinâmica de Uso da Terra em Senador José Porfírio - PA, Amazônia Oriental Valdinei Mendes Moura; José Antônio Magalhâes Marinho; Gabriel Alves Veloso

Figura 04 - Dinâmica espacial e temporal do usa da terra no município de Senador José Porfírio-PA

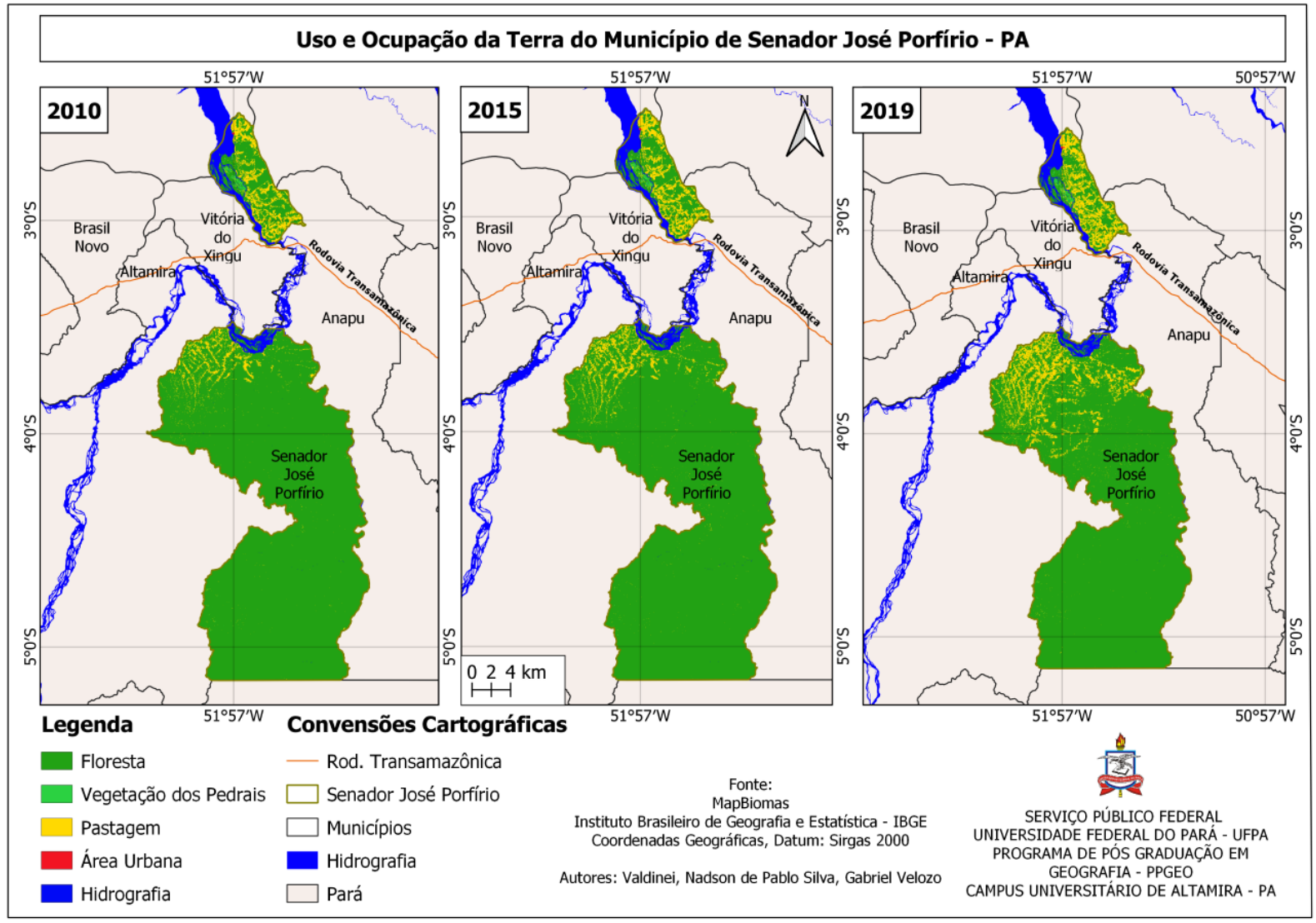

FONTE: MAPBIOMAS (2020)

Atualmente, nesse território, os recursos florestais se encontram ameaçados pela expansão dos pastos, sobretudo em áreas de assentamentos, como a gleba Bacajaí de posse do Estado do Para, e terras indígenas homologadas (Arara da Volta Grande do Xingu, Trincheira Bacajá, Paquiçamba, Koatinemo) e em fase de estudo como a Ituna/Itatá. Nesse sentido, o avanço das áreas de pastagens para prática da pecuária extensiva, particularmente na porção sul do município constitui um vetor de uso e ocupação da terra que está relacionado às tensões e conflitos fundiários e, sobretudo, à dinâmica de desmatamento, inclusive no interior de terras indígenas.

O resultado das transformações da paisagem (floresta ombrófila) no município de Senador José Porfírio-PA se relaciona aos interesses do capital, nesse caso não pela transformação da paisagem "em si”, mas "para si" capitalizar o uso da terra por pastagens objetivando negociá-la posteriormente com maior taxa de lucro. 


\section{A DINÂMICA DO EXTRATIVISMO MADEIREIRO}

A extração de madeira sempre se mostrou uma atividade muito intensa no município de Senador José Porfírio. Essa atividade começa a se desenvolver nesse município desde os anos 1970, com a chegada das primeiras Serrarias, e nas décadas seguintes, expandiu-se, contando com o acesso aos ricos estoques de madeira e com incentivos das gestões municipais, que disponibilizavam espaços para a instalação dos empreendimentos ligados a atividade madeireira (MOURA, 2018). No entanto, os dados do IBGE sobre a dinâmica dessa atividade em Senador José Porfírio, no período de 2010 a 2014, não indicam crescimento da atividade madeireira, como se observa no quadro 2 a seguir.

Como se observa nesse quadro, o volume de madeiro registrado no período de 2010 a 2014 é modesto em termos de quantidade e receita, mas não se deve desconsiderar, porém, que a extração ilegal de madeira perdura em todo o território do município nos dias atuais. Nota-se que esses números oficiais expressos no quadro sobre a exploração madeireira em Senador José Porfírio-PA, devem ser vistos com cautela, uma vez que parte dessa atividade se desenvolve numa zona que não é alcançada pelas estatísticas dos órgãos oficiais.

Quadro 2 - Produção de Madeira em Tora em Senador José Porfírio (2010-2014)

\begin{tabular}{|c|c|c|}
\hline ANO & $\begin{array}{c}\text { QUANTIDADE } \\
\text { PRODUZIDA }\left(\mathbf{M}^{\mathbf{2}}\right)\end{array}$ & VALOR PRODUÇÃO (R\$) \\
\hline $\mathbf{2 0 1 0}$ & 44.816 & $5.378,00$ \\
\hline $\mathbf{2 0 1 1}$ & 43.200 & $6.480,00$ \\
\hline $\mathbf{2 0 1 2}$ & 50.423 & $9.076,00$ \\
\hline $\mathbf{2 0 1 3}$ & 17.759 & $3.392,00$ \\
\hline $\mathbf{2 0 1 4}$ & 20.000 & $3.800,00$ \\
\hline
\end{tabular}

Fonte: IBGE (2020)

Apesar de constituir um importante setor da economia municipal, o setor madeireiro opera em grande parte do tempo sem o devido acompanhamento dos órgãos de fiscalização, produzindo implicações ambientais variadas, tanto no entorno das serrarias, que fazem os restos de madeiras avancem sobre praias e margens de rio, bem como, sobre áreas de cobertura vegetal do município, empobrecendo-a, e por vezes, um primeiro passo para o desmatamento completo e instalação de pastagens (MOURA, 2015).

Além disso, como assinalam PACHECO et al. (2009), Anapu e Senador José Porfírio são municípios que se caracterizam como áreas mais recentes de exploração, atraindo 
madeireiros de municípios próximos (Uruará e Medicilândia), onde os estoques naturais de madeireira se esgotam. Em 2014, por exemplo, uma parte do município conhecida como área da REICOM (Rebelo Indústria Comércio e Navegação) foi ocupada e amplamente explorada por madeireiros que, posteriormente, pressionaram o INCRA a consolidá-la em assentamento, o Castanheira II (INCRA, 2014; IBAMA, 2014).

Tais pressões vale lembrar, articulam interesses locais e iniciativas nacionais, condicionando a ocupação da terra em Senador José Porfírio, no qual essas ações e disputas envolvendo sujeitos sociais diversos, tais como camponeses, posseiros, grileiros e latifundiários. Ademais, atualmente a extração madeireira minimizou-se principalmente na porção norte municipal (sede do município), e essa atividade vem sendo progressivamente desenvolvida ilegalmente na parte ocidental da Floresta Nacional de Caxiuanã (ÁREA: 317.946,37 ha / DIPLOMA LEGAL DE CRIAÇÃO: Dec nº 239 de 28 de novembro de 1961).

Evidentemente, se compreende que essas intervenções territoriais no espaço natural atingem a dinâmica biológica e ecológica de ecossistemas encontrados na Região Integrada do Xingu. É sabido, porém, que partes desses madeireiros foram atraídos para a região em função do fluxo populacional que se direcionou com a construção da usina hidrelétrica de Belo Monte em meados de 2014, e desde então, aproveitam-se do momento histórico e da ausência de fiscalização eficiente de órgãos competentes para extrair madeira desordenadamente, viabilizada por redes de estradas e ramais na região interligada à Rodovia Transamazônica até os dias atuais.

Essas intervenções antrópicas vêm provocando impactos sociais e degradações ambientais que perduraram até os dias atuais no território municipal, que também são potencializadas pela instalação de grandes projetos de exploração dos recursos naturais na área conhecida como Volta Grande do Xingu, além disso, essa atividade madeireira vem avançando sobre as terras indígenas localizadas ao sul do município.

Há décadas, esta região sofre com a fragmentação e a perda de habitat, causados principalmente pelo crescimento populacional desordenado e pela inserção de novas atividades econômicas, como extração madeireira, agropecuária e geração de energia (VIEIRA et al, 2008).

\section{AS MUDANÇAS DESENCADEADAS PELOS GRANDES PROJETOS NA VOLTA GRANDE DO XINGU}


Na área da Vota Grande do Xingu, a instalação da UHE Belo Monte e a iminente implantação do Projeto Belo Sun, visando à exploração mineraria em Senador José Porfírio, desencadearam processos geográficos contraditórios, que incidiram no uso da terra e da água, evidentemente.

A construção da UHE Belo Monte, chama a atenção para o fato de que o Trecho de Vazão Reduzida (TVR), formado a jusante do barramento principal dessa hidrelétrica na Volta Grande do Xingu, dificulta o acesso a localidades como Ilha da Fazenda, Ressaca e áreas adjacentes, incluído Terras Indígenas (TI’s), situadas em Senador José Porfírio. Ademais, devido à redução do volume de água no leito do rio na região da Volta Grande do Xingu, tem provocado efeitos negativos na pesca, atividade essencial ao modo de vida dos ribeirinhos nessas localidades (MOURA, 2015).

Depois da inauguração da parcial da UHE Belo Monte em 2015, esta modificou profundamente a dinâmica natural do rio Xingu, e trouxe muitas incertezas aos moradores do trecho de TVR do empreendimento, pois o regime do rio Xingu tornou-se estranho aos grupos ribeirinhos, de modo que esses grupos já tiveram plantações e embarcações arrastadas por um fluxo repentino decorrente da abertura de comportas da barragem principal, além de tornar esse trecho inavegável (CHAVES, 2018).

Dessa forma, a construção da UHE redefiniu a relação sociedade-natureza na Volta Grande do rio Xingu, atingindo fortemente o modo de vida dos grupos sociais ribeirinhos que, contraditoriamente, por estarem num trecho do rio que não iria submergir, mas perder vazão, não foram considerados como atingidos pelo empreendimento, ficando assim, sem direitos a indenizações e/ou reassentamento. Outro grande empreendimento em vias de instalação na Volta Grande do Xingu, na porção territorial sul de Senador José Porfírio, é o Projeto Belo Sun, que se trata de um projeto de mineração, capitaneado por uma empresa mineradora canadense, cujo licenciamento ambiental encontra-se suspenso. Mesmo assim, a iminência de instalação desse projeto já estaria desencadeando processos de especulação fundiária e conflitos por terra.

O eventual avanço do processo de licenciamento do projeto Belo Sun, junto com a mudança do cenário político, que tende a facilitar a concentração fundiária, podem agravar o processo de ocupação e desmatamento no município de Senador Porfírio, o que já pode estar ocorrendo, inclusive no interior de Terras Indígenas, áreas que por lei estaria mais protegida desse processo de degradação ambiental (ISA, 2018).

Em consequência, nessa região da Volta Grande do Xingu, visando coibir essas pressões socioambientais, a associação local Associação dos Produtores Rurais das Glebas Ituna, Bacajá e Bacajaí - APRIBAI vem reivindicando a regularização fundiária deste Projeto 
de Assentamento Estadual Agroextrativista - PEAEX, perante aos órgãos competentes do estado do Pará, através de um processo de ordenamento territorial junto a Defensoria Pública do Estado. Porém, mesmo assim, nos últimos anos, a dinâmica de desmatamento não parou de avançar no território do PEAEX.

A reivindicação está orientada oficialmente pelo discurso da preservação ambiental, visto que o interior deste território se tornou palco de diversos conflitos pelo uso da terra em que vem desencadeando profundas mudanças sociais e ambientais.

No território do PEAEX Napoleão Santos tais processos vêm promovendo expressivas mudanças através do avanço das atividades agropecuárias, madeireiras e minerárias, no qual essas pressões socioambientais vêm produzindo novos espaços geográficos ao suprimirem a vegetação nativa, chamando a atenção principalmente pelos danos ambientais. A ação de agentes interessados em explorar e/ou apropriar-se de áreas ainda florestadas e de recursos minerários no seu interior, vem alavancando o desmatamento e ameaçando, não apenas a biodiversidade, mas os modos de vida de comunidades agroextrativistas que ocupam o território. Desta forma, o acompanhamento dessa dinâmica de uso e ocupação da terra no PEAEX Napoleão Santos é de significativa importância, devido ao contexto em que está inserida, com altos investimentos públicos de infraestrutura, especialmente o de geração de energia, produção e manutenção de rodovias.

Todavia, frente a essas transformações, o território do PEAEX Napoleão Santos passou (e ainda vem passando) por um processo de ordenamento territorial, sendo que o uso e ocupação da terra de forma intensa vêm resultando em danos significativos ao meio ambiente. Ao passar dos anos as disputas pela terra e seus recursos impulsionaram relações extremamente violentas dentro deste território, prevalecendo uma gestão territorial baseada na ilegalidade, gerando processos de intimidações e embate aos menos favorecidos (AMORIN; HERRERA; SANTOS, 2019).

\section{A DINÂMICA ESPAÇO-TEMPORAL DO DESMATAMENTO}

A dinâmica dos desmatamentos na Amazônia, não pode ser explicada apenas por uma variável ou processo de ocupação do solo, devido à dimensão da região e à escala em que se dão os desmatamentos. Entretanto, os processos de degradação ambiental na Amazônia não podem ser dissociados do avanço da propriedade privada da terra e da transformação progressiva da natureza em mercadoria, através da exploração dos recursos naturais a partir de uma racionalidade estritamente econômica que se sobrepõe às demais formas de uso dos rios, da terra e das florestas na região (MARGULIS, 2003). 
As transformações antrópicas em Senador José Porfírio se relacionam a pressões por novos espaços para exploração da madeira e para criação de pastagens, processos que muitas vezes são complementares e moldados em consonância com as dinâmicas territoriais dos agentes do capital articulados em diferentes escalas. $\mathrm{O}$ avanço desses processos de apropriação e uso da terra neste município está por traz dos crescentes índices de desmatamento, que vem apresentando crescimentos progressivamente ao longo do tempo. São essas atividades antrópicas que produzem o espaço, portanto, compreender o processo de evolução de uso e ocupação da terra nos remete a uma compreensão multiescalar. Esse processo evolutivo de uso e ocupação da terra se deu através dessas interações multiescalares, veiculadas por uma rede de estradas, ramais e travessões interligada ao rio Xingu e à predominante BR 230 (Transamazônica) o que vem viabilizando redes de comunicação, a comercialização da terra e a produção territorial.

Esses avanços que vêm acontecendo nos últimos anos, pode estar relacionado com a conjuntura política nacional, em que o governo federal explicitou reiteradamente a intenção de enfraquecer os órgãos ambientais de controle e fiscalização ambiental, alimentando com isso maiores expectativas naqueles que pleiteiam se apropriar e explorar mais terras. A Figura 5 a seguir demonstra a evolução do desmatamento no município entre os anos de 2010 a 2019 (PRODES, 2020).

Em âmbito local, esses desmatamentos intensificaram os problemas socioambientais e paisagísticos relacionados às dinâmicas socioespaciais concretizadas por redes de estradas, rios e até pistas de pouso, uma vez que existem além de hidrovias e redes de estradas no território, pistas para pequenos aviões, usadas pelos agentes promovem a remoção da cobertura vegetal nativa e instalação de pastagens (IBAMA, 2019). Na rodovia PA 167, que interliga a cidade de Souzel (sede municipal) rodovia 230 - Transamazônica esse processo avança. Ainda assim, deve-se ressaltar que o desmatamento em Senador José Porfírio se eleva por toda a série histórica considerada, fazendo com que as áreas de florestas no município também fossem regredindo, como se observa na figura 5 a seguir.

As estratégias de territorializações de uso e ocupação da terra no município de Senador José Porfírio-PA, acontecem desordenamento através da força econômica que já faz parte da rotina dos sujeitos sociais que ocuparam e vem produzindo o território muitas vezes a partir de ações violentas. A violência passou a fazer parte dos cotidianos das famílias de camponeses que ali se instalaram, muito desse movimento conflituoso foi possibilidade pelo conjunto de ações e políticas do estado brasileiro afim de apropriação dos recursos aqui dispostos (AMORIN; HERRERA; SANTOS, 2019). 
Dinâmica de Uso da Terra em Senador José Porfírio - PA, Amazônia Oriental Valdinei Mendes Moura; José Antônio Magalhâes Marinho; Gabriel Alves Veloso

Figura 05: Área de desmatamento no município estudado.

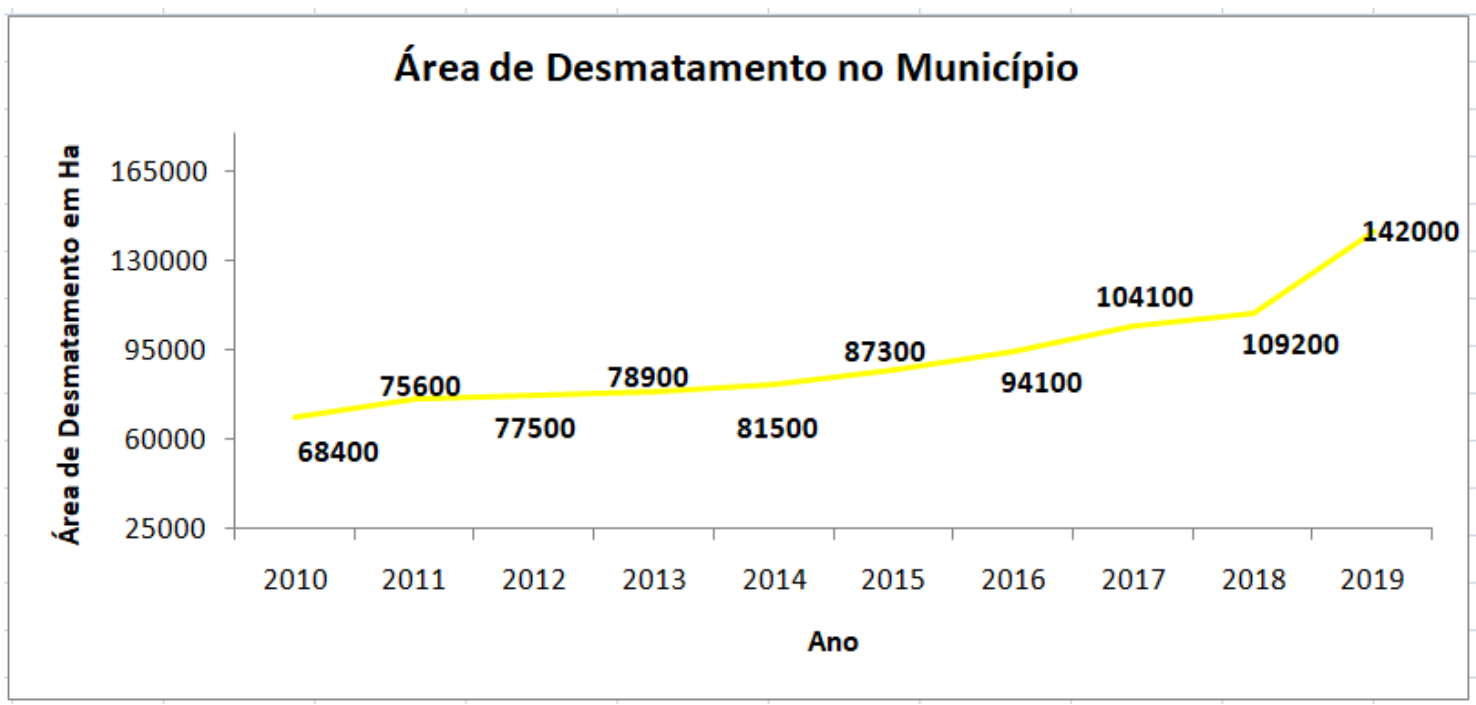

Fonte: PRODES (2020)

Figura 06 - Áreas de Floresta no Município em MHa.

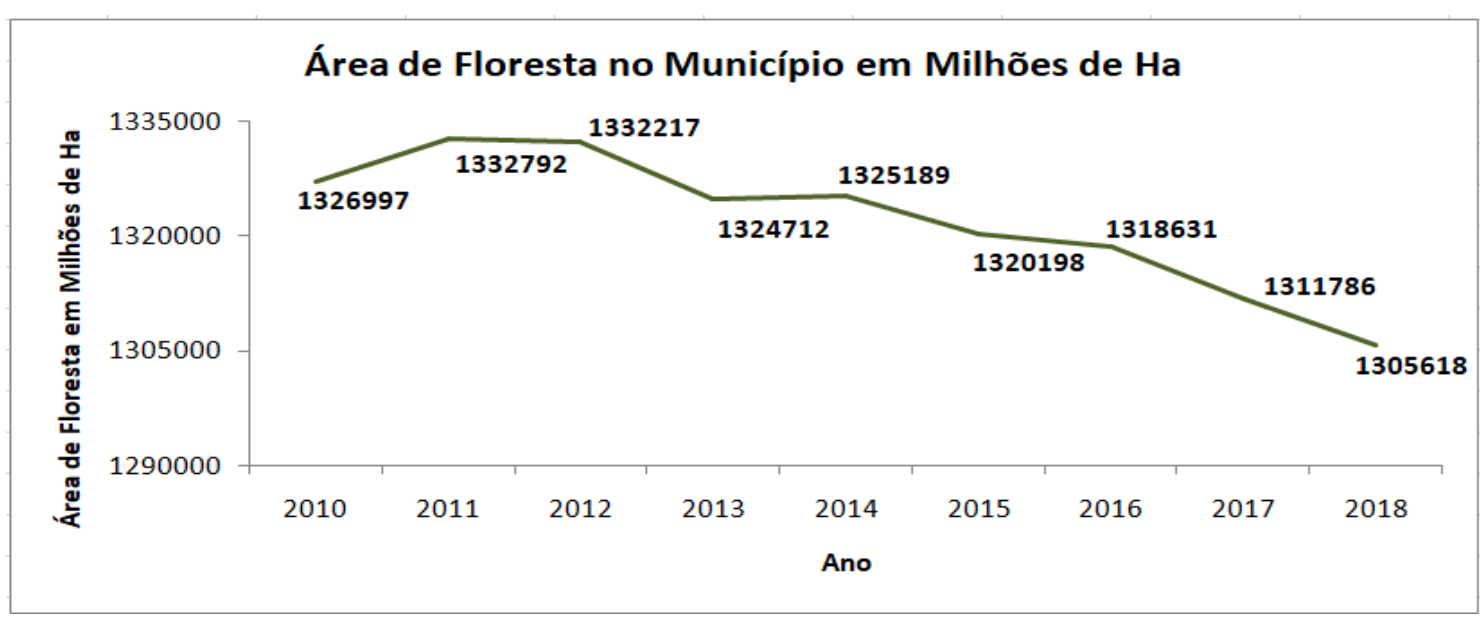

Fonte: MAPBIOMAS (2020)

Ainda assim, deve-se ressaltar que o desmatamento em Senador José Porfírio se eleva por toda a série histórica considerada, fazendo com que as áreas de florestas no município também fossem regredindo, como se observa na Figura 6. Esse processo de desmatamento vem avançando também sobre as áreas de terras indígenas, na porção sul do território de Senador José Porfírio.

Verifica-se que a incidência do desmatamento vem avançando nos territórios indígenas com destaque para o ano de 2018. Os dados do MAPABIOMAS (2020) demonstram que especialmente na TI Ituna/Itatá (Figura 7), o crescimento se acentua, sobretudo a partir de 
2014, ano em que se maximiza a grilagem de terras na zona de influência da Hidrelétrica de Belo Monte, na volta grande do Xingu (ISA, 2020).

Ademais, as áreas das terras indígenas compreendem, com exceção da TI Arara da Volta Grande do Xingu, tanto o município de Senador José Porfírio, quanto a outros municípios como Altamira-PA (TI Ituna/Itatá, Koatinemo, Arawete/Igarapé Ipixuna), Anapú-PA (TI Trincheira Bacajá) e São Félix do Xingu (TI Trincheira Bacajá).

Dentre as terras indígenas localizadas no território porfiriense, se destaca a Terra indígena Ituna/Itatá, pois esta foi a TI mais desmatada da bacia do Xingu em 2018, totalizando, 6.785 ha desmatados ao longo do ano, o que significou um aumento de $86 \%$ em comparação a todo o desmatamento acumulado até 2017 (ISA, 2018). Para este sistema, cerca de $87 \%$ dessa Terra Indígena é sobreposta à registros irregulares do Cadastro Ambiental Rural.

Figura 07 - Áreas da Agropecuária nos Territórios Indígenas.
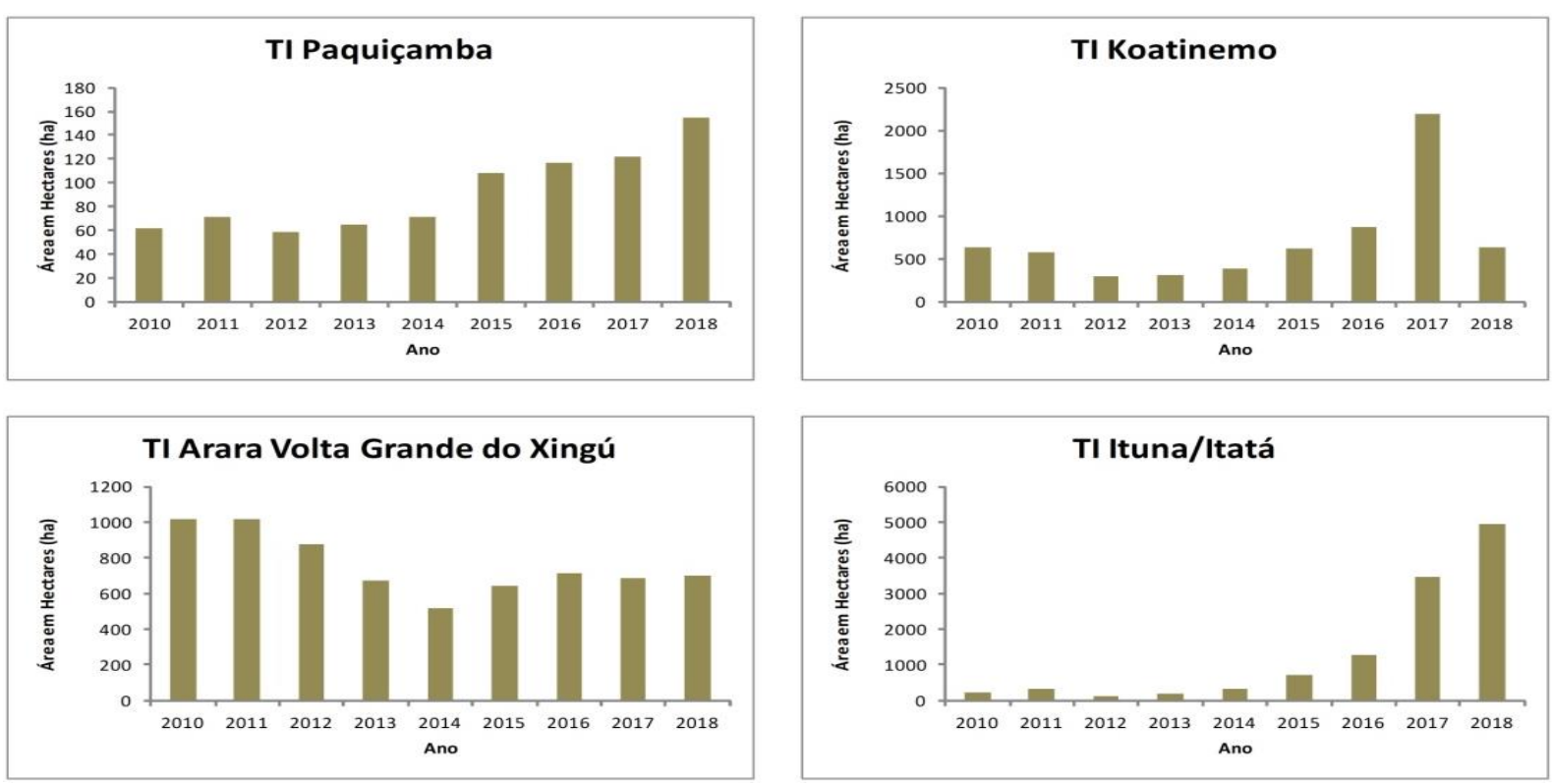

Fonte: MAPBIOMAS (2020)

Essas pressões socioambientais produziram, historicamente, novas áreas ao suprimirem a vegetação nativa, chamando a atenção principalmente pelos danos ambientais. Em consequência, visando coibir essas pressões socioambientais, com uma área de 25.534,26 ha, esta terra indígena passou por um processo de ordenamento territorial, orientado oficialmente pelo discurso da preservação ambiental, o que resultou em sua homologação em 20 de abril de 2015 (ISA, 2020). 
Figura 08 - Desmatamento na terra indígena Koatinemo, no sudoeste do Pará.

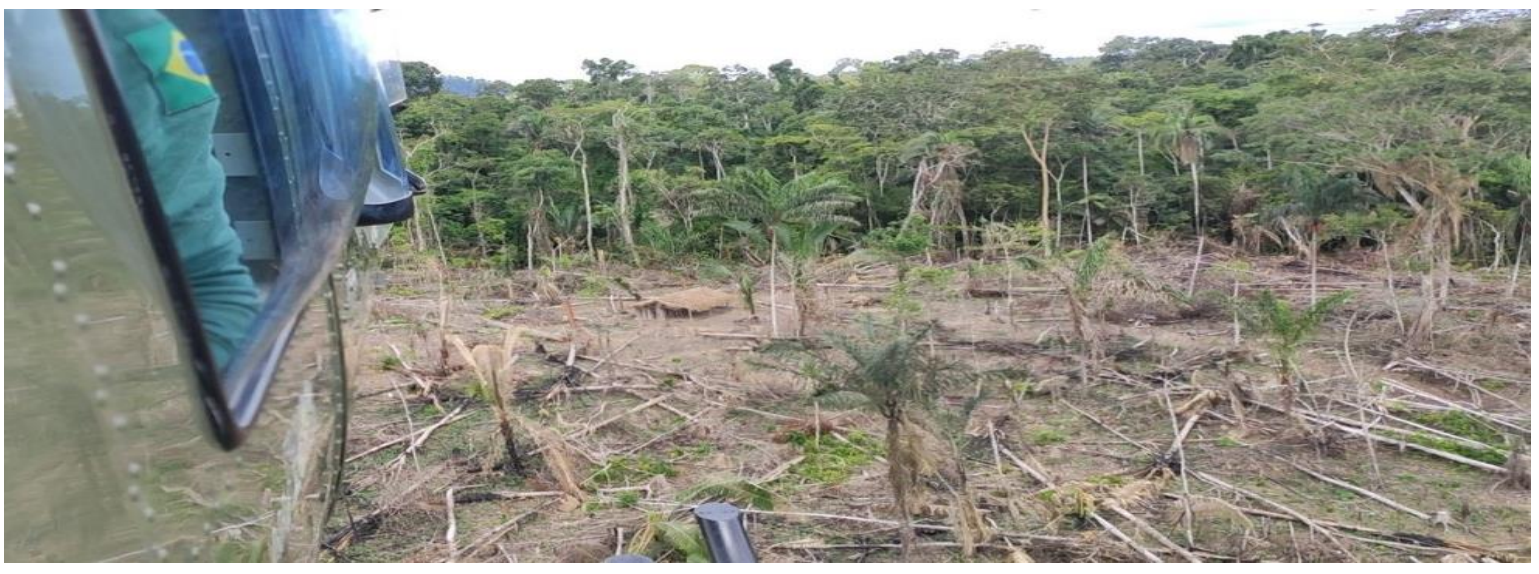

Fonte: IBAMA (2020).

Demonstra-se nessa figura (08) que o desmatamento em terras indígenas está atrelado aos interesses do capital, pois nesse início de século XXI acentuou-se, especificamente no município de Senador José Porfírio, a política de ocupação e desenvolvimento econômico da região da Amazônia oriental, neste caso ilegalmente (IBAMA, 2019). Nesse processo, na região da Amazônia oriental, ao que tange o município de Senador José Porfírio, acentuaram-se os conflitos de interesses e de territorialidades, isto é, a disputa por territórios entre os grupos ou protagonistas sociais, desfavorecendo os de menor poder político e econômico, como os povos agroextrativistas, camponeses, ribeirinhos e indígenas.

Esse processo deu preferência ao grande capital, ou seja, as grandes empresas agropecuárias, de mineração internacional (Belo Sun) e de geração de energia (Hidrelétrica de Belo Monte), no qual esses processos irão acentuar ainda mais as pressões, desencadeando tensões sociais e degradação ambiental, que tendem a se agravar ainda mais.

\section{CONSIDERAÇÕES FINAIS}

A dinâmica de uso e terra no município de Senador José Porfírio demostrou-se complexa, devido a sobreposição de várias atividades de diversos agentes sociais e políticos, no qual vem impulsionando uma série de alterações no espaço geográfico. Pode-se constatar que o crescente processo de desmatamento das áreas de Florestais do município pode ter relação com o processo de expansão da pecuária extensiva, bem como, com a exploração ilegal da madeira. Além disso, pode-se concluir que às implicações territoriais desencadeadas pela instalação da UHE Belo Monte pode ter influenciado esses processos, bem como, observou-se 
que as estratégias de apropriação terra com a remoção da cobertura vegetal geralmente constitui uma das primeiras ações.

Dentre as áreas das Terras Indígenas que apresentaram maior taxa de desmatamento foram as TI Ituna/Itatá e Paquiçamba, sobretudo entre os anos de 2015 a 2018. Já a TI Arara da Volta Grande do Xingu manteve-se uma taxa de desmatamento estável no período analisado, e a TI Koatinemo apresentou uma alta taxa de desmatamento no ano de 2017, mas manteve a menores médias de desmatamento no período analisado.

Pode-se constatar também que a expansão da agropecuária extensiva tem forte influência na redução das áreas de floresta, pois nos dados analisados observou que quando as áreas de pastagem expandem as áreas de floresta apresentaram redução. Portanto, essas transformações ocorridas no território do município de Senador José Porfírio são realizadas por diferentes sujeitos sociais, sendo que os impactos são causados sobretudo em áreas de floresta, no qual esse resultado está relacionado diretamente com o desmatamento, queimadas e consequentemente com a degradação do solo. Essa produção territorial culmina com diferentes forças, sejam elas: políticas, econômicas e sociais que produzem esse território conflituosamente através de interesses antagônicos, no qual os sujeitos sociais desprovidos de forças políticas e econômicas sempre são os mais prejudicados.

\section{REFERÊNCIAS}

AMORIM, E. B.; HERRERA, J. A.; SANTOS, T. S. Território e conflitos agrários na amazônia paraense, um estudo a partir dos conflitos pela terra em Anapu-PA. USP, XIII ENANPEGE (2019).

BARATA, R. Inventário da violência: crime e impunidade no campo paraense, 1980-1989. Belém: Cejup, 1995.

BARRETO, A. M. Apropriação ilícita de terras públicas na Amazônia: o caso gleba Ituna, no estado do Pará. Amazônia, v. 3, p. 7-25, 2007.

BORGES, L. R. M. Políticas territoriais e setor elétrico no Brasil: análise dos efeitos da construção de hidrelétricas na Amazônia pelo programa de aceleração do crescimento no período de 2007 a 2014. Tese (Doutorado em Geografia Humana) - Faculdade de Filosofia, Letras e Ciências Humanas, Universidade de São Paulo, São Paulo 2018.

BRUN, E. Senador José Porfírio, Pará, Amazônia: altíssimo risco: Um projeto que pode ser mais destruidor do que Belo Monte está em disputa no Xingu e os brasileiros não estão nem aí. El PAÍS, Brasil, Opinião, dez. de 2017. Disponível em:

https://brasil.elpais.com/brasil/2017/12/11/opinion/1512997340_266770.html. Acesso em 20 de julho de 2020. 
CANTO, O. MUDANÇAS ESTRUTURAIS NO TERRITÓRIO PARAENSE E A DINÂMICA POPULACIONAL NA REGIÃO DE INTEGRAÇÃO (RI) XINGU-PA. Geografia na Amazônia paraense: territórios e paisagens, $1^{\text {a }}$ edição gapta/ufpa Belém 2015 .

CHAVES, K. A. Agora o Rio vive seco: Populações tradicionais, exceção espoliação em face da instalação de grandes projetos na Volta Grande do Xingu, Rio Claro, 2018.

CORREAA, S. R. M. Neodesenvolvimentismo e conflitos sociais: o caso da Hidrelétrica de Belo Monte. Novos Cadernos NAEA, v. 19, p. 234-254, 2016.

FEARNISIDE, P. M. Desmatamento na Amazônia brasileira: história, índices e consequências. Megadiversidade, Manaus. v. 01, n. 01, p. 113 - 123, 2005.

FILHO, G. X. P; NERES, J. S. Dinâmica do desmatamento: uma análise à partir dos municípios de Anapu, Brasil Novo, Pacajá e Senador José Porfírio. 01. ed. Altamira - PA: Instituto Agronômico da Amazônia, 2016. v. 01. 119p.

GREENPEACE (2018). Disponível em: <https://doe.greenpeace.org.br/>. Acesso em: 13 jun. 2020 .

GREENPEACE (2020). Disponível em: <https://doe.greenpeace.org.br/>. Acesso em: 13 jun. 2020.

GREENPEACE. Ituna-Itatá: uma terra indígena da Amazônia tomada por ganância e destruição. Disponível em: https://www.greenpeace.org/brasil/ituna-itata-uma-terra-indigenada-amazonia-tomada-por-ganancia-e-destruicao/. Acesso em 15/04/2021.

IBAMA. Desmatamento: novo cálculo. 2012. Disponível em: <https://www.gov.br/mma/ptbr/noticias/desmatamento-novo-calculo >. Acesso em: 15 abr. 2021.

IBAMA. Instituto Brasileiro do Meio Ambiente e dos Recursos Naturais Renováveis. Disponível em: 〈https://www.ibama.gov.br/>. Acesso em 13 jun. 2020.

IBAMA. Instituto Brasileiro do Meio Ambiente e dos Recursos Naturais Renováveis. Projeto Quelônios da Amazônia - 10 anos, $1989 . \quad$ Disponível em: $\langle$ https://www.bdpa.cnptia.embrapa.br/consulta/busca?b=ad\&id=387865\&bibliote $>$. Acesso em: 13 jun. 2020.

IBGE. Área e produção agropecuária e extrativista por município, 2009. Disponível em: 〈https://www.ibge.gov.br/>. Acesso em: 20 jun. 2011

DESP. Índice de Desenvolvimento da Educação do Estado do Pará. Disponível em: <http://www.age.pa.gov.br/content/idesp〉. Acesso em: 16 jun. 2020.

IMAZON. Pecuária na Amazônia: Tendências e implicações para conservação ambiental. https://imazon.org.br/publicacoes/pecuaria-na-amazonia-tendencias-e-implic, [s.l.] 2015. 
Dinâmica de Uso da Terra em Senador José Porfírio - PA, Amazônia Oriental Valdinei Mendes Moura; José Antônio Magalhâes Marinho; Gabriel Alves Veloso

INCRA (2014). Instituto Nacional de Colonização e Reforma Agrária. Disponível em: <http://www.incra.gov.br/pt/>. Acesso em: 13 jun. 2020.

INSTITUTO SOCIOAMBIENTAL (ISA). Grandes empreendimentos provocam boom de desmatamento na Volta Grande do Xingu. Disponível em: <https://www.socioambiental.org/pt-br/blog/blog-do-xingu/grandes-empreendimentosprovocam-boom-de-desmatamento-na-volta-grande-do-xingu>. Acesso em: 13 jun. 2020.

ITERPA. Instituto de Terras do Pará. Disponível em: https://www.socioambiental.org/ptbr>. Acesso em: 13 jun. 2020.

MAIA, R. E. F.; GUERRA, G. A. D. POPULAÇÕES LOCAIS E HIDRELÉTRICAS: O caso de duas localidades atingidas pela barragem de Belo Monte, Pará, Brasil. Campo - Território, v. 10, p. 362-392, 2015.

MAPBIOMAS. Disponível em: 〈https://mapbiomas.org/>. Acesso em 02 jun. 2020.

MARGULIS, S. Causas do desmatamento na Amazônia Brasileira. Brasília, 2003.

MARINHO, J. A. M. As lutas camponesas e o cercamento do médio rio Xingu (PA): A construção da Hidrelétrica de Belo Monte. Tese de Doutorado apresentado ao Programa de Pós-graduação em Geografia Humana do Departamento da Faculdade de Filosofia, Letras e Ciência Humanas da Universidade de São Paulo, 2019.

MARTINS, F. A concepção de Missão no Projeto da Companhia de Jesus no Estado do Maranhão e Grão-Pará, no século XVII. [s.l.] In: NEVES, Fernando Arthur de Freitas;

MEIRELLES FILHO, J. C. S. É possível superar a herança da ditadura brasileira (1964-1985) e controlar o desmatamento na Amazônia? Não, enquanto a pecuária bovina prosseguir como principal vetor de desmatamento. Boletim do Museu Paraense Emílio Goeldi. [s.1.] Ciências Humanas, v. 9, n. 1, p. 219- 241, jan.-abr. 2014.

MMA/PAS, 2008. Disponível em: <https://www.mma.gov.br/>. Acesso em: 11 set. 2020.

MOURA, V. M. TRANSFORMAÇÕES NAS PRIORIDADES SOCIOAMBIENTAIS EM SENADOR JOSÉ PORFÍRIO-PA APÓS CONSTRUÇÃO DA HIDRELÉTRICA BELO MONTE. Dissertação (Programa de Pós-Graduação em Desenvolvimento Regional) Centro Universitário Alves Faria-Unialfa, Goiânia-GO, 2015. 188 p.

MPF (Ministério Público Federal). Disponível em: <http://www.mpf.mp.br/>. Acesso em: 11 jul. 2020.

OLIVEIRA, A. U. de O. Relatório técnico do trabalho de campo no pontal do Paranapanema e são Félix do Xingu/pa. [s.l.] In. SÉRIE PENSANDO O DIREITO, n 48, 2017.

PLANO DE DESENVOLVIMENTO REGIONAL SUSTENTÁVEL DA REGIÃO DE INTEGRAÇÃO XINGU. Resumo Executivo. Universidade Federal do Pará. Núcleo de Altos Estudos Amazônicos - [s.1.] UFPA/NAEA. 
PRODES. Disponível em: 〈http://www.dpi.inpe.br/prodesdigital/prodesmunicipal.php〉. Acesso em: 02 jun. 2020.

SERRÃO, A. M.; CRUZ, M. J. M. Geografia das colônias agrícolas no médio rio Amazonas, município de Urucará-AM. CONFINS (PARIS), v. 43, p. 1-20, 2019.

SILVA, E. P. da. Terras e territórios tradicionais da Volta Grande do Xingu na mira de megaempreendimentos minerais. In: Alfredo Wagner Berno de Almeida et al. (Org.). Mineração e Garimpo em Terras tradicionalmente ocupadas: conflitos sociais e mobilizações étnicas. 1ed. Manaus: UEA Edições/PNCSA, 2019, v. 1, p. 376-392.

TORRES, M. Situação fundiária caótica. In: André VILLAS-BOAS. (Org.). De olho na Bacia do Xingu. 1ed. São Paulo: Instituto Socioambiental, 2012. p. 32-39.

TORRES, M. Dono é quem desmatamento: conexões entre grilagem e desmatamento no sudoeste paraense. [s.l.]: Urutu-branco; Altamira: Instituto Agronômico da Amazônia, 2017.

Artigo recebido em: 26 de fevereiro de 2021. Artigo aceito em: 11 de maio de 2021. Artigo publicado em: 01 de julho de 2021. 